\title{
Effect of Boron and Myo-Inositol on Pollen Tube Growth of Hybrid of Bread Wheat (Triticum Aestivum L. Emend. Thell.)
}

\author{
A. B. Mandal ${ }^{\mathrm{a}}$ and A. Sharma ${ }^{\mathrm{b}}$ \\ ${ }^{a}$ Bidhan Chandra Krishi Viswavidyalaya, Mohanpur 741252, West Bengal \\ ${ }^{b}$ Assistant Director of Agriculture (Administration), Malda Sadar 732101
}

\begin{abstract}
A study was made on the pollen tube growth of bread wheat (Triticum aestivum L.) in vivo at different intervals of time by the application of $0 \mathrm{ppm}, 10 \mathrm{ppm}, 15 \mathrm{ppm}$ of borax and $50 \mathrm{ppm}$ of myo-inositol through spraying. Pollen germinated normally on the stigmatic papillae, pollen tube emerged from the germinating pollen tube and passed through the stigmatic papillae in both the situation i.e. treated and untreated ones. After then interesting results were observed. The length of pollen tube of different treatments increased significantly at different intervals of time as compared to control except for $T_{1}$ treatment where tube length was not significant at 3, 4, 6 hours. However, when the results of different treatments were compared $T_{2}$ emerged as the best treatment followed by $T_{3}$. At 6 hours a few of the germinating pollen tubes reached the style for $T_{2}$ and $T_{3}$ treatments. But till then no styles received any pollen tube for $T_{0}$ and $T_{1}$ treatments. At that time the germinating pollen tube reached a short distance of the style through the transmitting tissues of the style which consisted of compacted and elongated cells.
\end{abstract}

Keywords: Boron susceptible, stylar incompatibility, stigmatic pappilae, myo-inositol

\section{Introduction}

A number of studies on the pollen tube growth of different crop species in vivo has been made but the study on growth of the pollen tube in vivo is limited. On graminae this aspect has received scant attention. Fragmentary informations are available for maize (Randolph, 1936), Oat (Brown and Shands, 1957), barley (Luxova, 1967), rice (Cho, 1956). In wheat (Triticum aestivum Linn. Emend. Thell.) in vivo pollen germination (Kihara and Hori, 1966) and pollen tube growth (Chandra and Bhatnagar, 1974, Neumann and Naether, 1980, Jalani and Moss, 1980; Zeven and vanheermert, 1970) in near and distant crosses has been studied in details but information regarding the different factors affecting successful pollen tube entry into the style and ovary have not been highlighted.

Boron, a micro-nutrient is essential for crop growth. It regulates the different functions in plant. Therefore, due to its deficiency the different functions of plant are affected. Boron deficient soil has been reported from different countries of the world. In India its deficiency was reported from the arid and humid zone. In West Bengal, India this deficiency was reported from humid zone of North Bengal. In this zone due to high rainfall and sandy texture of soil most of the micro-nutrients like Boron, Zinc etc. leached through the soil layer. Due to deficiency of this nutrient partial to almost incomplete grain filling in the spike is a common occurrence in most of the Mexican semi dwarf wheat varieties (Ganguli, 1979; Chatterjee et al., 1980; Mandal and Das, 1988).

In West Bengal at Late sown condition $\left(20^{\text {th }}\right.$ December) loss of grain yield for certain boron susceptible varieties was 54\% in bread wheat (Mandal et al., 2014). The present study was, therefore, undertaken with a view to visualize the effect of boron and myo-inositol on in vivo pollen tube growth of BAU 2186, a boron susceptible variety in bread wheat at late sown condition.

\subsection{Experimental sites}

\section{Materials and Methods}

The experiment was conducted in the University Research Farm situated at Kalyani, longitude $22^{\circ} 99^{\prime}$ $\mathrm{N}$ and latitude $88^{\circ} 43^{\prime}$ experienced hot and semi humid climate with an annual rainfall of $\sim 1480 \mathrm{~mm}$ and maximum and minimum temperature $36.2 \pm 2.0^{\circ} \mathrm{C}$ and $12.5 \pm 1.0^{\circ} \mathrm{C}$ respectively. The soils were Aeric endoaquepts with loam texture, neutral reaction, medium in available $\mathrm{N}\left(415-440 \mathrm{~kg} \mathrm{ha}^{-1}\right), \mathrm{P}\left(20-25 \mathrm{~kg} \mathrm{ha}^{-1}\right), \mathrm{K}$ $\left(150-165 \mathrm{~kg} \mathrm{ha}^{-1}\right)$ and B content $0.6 \mathrm{ppm}$ requiring B application. 


\subsection{Cultivars used}

One boron susceptible variety BAU2186 and one boron resistant variety Sonalika were used for the present study. These two varieties were collected from the co-ordinated wheat project operating to the university.

\subsection{Management practices}

The seeds of two wheat cultivars were sown at the rate of $120 \mathrm{~kg} \mathrm{ha}^{-1}$ in the crossing block at Kalyani during 23 December for late sown condition. The row to row distance was $1 \mathrm{~m}$ and distance between plants within the row was $10 \mathrm{~cm}$. Five irrigations were given $\left(80 \mathrm{~L}\right.$ water $/ \mathrm{m}^{2} /$ irrigation $)$ at the time of sowing, crown root initiation, maximum tillering, flowering and grain filling stages. Fertilizers $\mathrm{N}: \mathrm{P}_{2} \mathrm{O}_{5}: \mathrm{K}_{2} \mathrm{O}$ 120:60:60 respectively were applied on the basis of soil test during final land preparation. Half of the dose of nitrogen was given at the time of sowing and the other half at maximum tillering stage (42 DAS). The entire amount of P and $\mathrm{K}$ in the form of single super phosphate and muriate of potash respectively were applied during time of sowing. Other management practices as recommended by the university were followed to raise the crop.

\subsection{Emasculation}

Variety BAU 2186 was used as female parent. Relatively young spike were selected for emasculation. Only side florets of each spikes were used for emasculation and middle florets were removed from the spike. Less than half of each floret was incised without damaging the pistil by a fine scissor. Anthers from each floret were removed with the help of a fine forcep. Ten spikes per treatment were emasculated. After emasculation required dosages of borax and myo-inositol solution were sprayed on the florets of each spike with the help of a fine sprayer barring control ones. The different dosages of solution of borax and myo-inositol were as follows : $\mathrm{T}_{\mathrm{o}}=$ Control; $\mathrm{T}_{1}=10 \mathrm{ppm}$ of borax, $\mathrm{T}_{2}=15 \mathrm{ppm}$ of borax, $\mathrm{T}_{3}=50 \mathrm{ppm}$ of myo-inositol.

2.5 Bagging

After spraying the emasculated spikes of treated and control ones were covered with butter paper bags and labelled properly with the help of jewellery label.

\subsection{Pollination}

Pollination was made 70 hours after emasculation. During pollination fresh pollens were collected from Sonalika on 10 A.M. and dusted on the stigmata of the florets so that sufficient pollens adhered to the feathery stigmata.

\subsection{Fixation}

After pollination pistils from treated and untreated ones were collected from the spikelets carefully. They were fixed immediately at different hours of intervals viz., 1/2, 1, 2, 3, 4 and $6^{\text {th }}$ hour after pollination in acetoalcohol (1:3) in separate tubes. Proper labelling was done on the fixative tubes indicating time interval and treatment. The tubes were stored in a refrigeractor.

\subsection{Observation}

For studying the growth of pollen tube through stigmatic and stylar tissues, the pistils were stained in $0.1 \%$ lactophenol cotton blue stain. For proper staining the materials were kept in stain for 24 hours and excess stain was washed out in lactophenol. After destaining styles from each pistil were dissected from the ovary and mounted in diluted lactophenol on clear slides. 20 pistils were taken for observation for each treatment.

Length of pollen tube for each treatment was recorded by ocular micrometer and converted in millimicron (m $\mu$ ). Micro-photography was taken from the clear slides.

\subsection{Statistical observation}

T-test was made to find out the differences of growth of pollen tubes for different treatments by the following formula :

$$
\begin{aligned}
& \mathrm{t}=\frac{\overline{\mathrm{x}}_{1}-\overline{\mathrm{x}}_{2}}{\delta_{c} \sqrt{\frac{1}{\mathrm{~N}_{1}}+\frac{1}{\mathrm{~N}_{2}}}} \\
& \delta_{\mathrm{c}}^{2}=\frac{\left(\mathrm{x}_{1}-\overline{\mathrm{x}}_{1}\right)^{2}+\left(\mathrm{x}_{2}-\overline{\mathrm{x}}_{2}\right)^{2}}{\mathrm{~N}_{1}+\mathrm{N}_{2}-2}
\end{aligned}
$$

where $\bar{x}_{1}=$ Mean length of pollen tube of one treatment and $\bar{x}_{2}=$ Mean length of pollen tube of other treatment $\mathrm{N}_{1}, \mathrm{~N}_{2}=$ Number of observations of two different set, Degree of freedom (d.f.) $=\mathrm{N}_{1}+\mathrm{N}_{2}-2$ 


\section{Results}

Pollen grains on the treated and untreated stigmatic papillae of wheat germinated normally (Fig. 1). After germination of the pollen tubes grow through these hairs. Table 1 depicts the mean length of pollen tubes at different hours of growth. Results of the experiment showed that at untreated conditions $\left(\mathrm{T}_{\mathrm{o}}\right)$ the growth of pollen tube between $1 / 2$ and 1 hour and 2 and 3 hours were comparable because ' $t$ ' values for these were significant (Table 2). However, ' $t$ ' values between 3 and 4 and 4 and 6 hours were not significant. Upto 6 hours at untreated condition no stylar tissues received any germinating pollen tubes. Whereas in treated ones observations were somewhat different. For $\mathrm{T}_{1}$ treatment $(10 \mathrm{ppm}$ of borax $) \mathrm{t}$ values for different combinations were not significant. This indicated that growth of pollen tubes were very slower. For $\mathrm{T}_{2}$ treatment $(15 \mathrm{ppm}$ of borax), however, the result was completely different. The growth of pollen tube between $1 / 2$ and $1,2,3$ and 3 and 4 hours were comparable as their respective ' $t$ ' values were significant. For $T_{3}$ treatment (50 ppm of myoinositol) the growth rate of 1 and 2 hours was significant only. When the length of pollen tube of untreated one was compared with treated ones notable observations were registered. From table 2 it was seen that the length of pollen tubes of untreated ones at 1/2,1 and 2 hours were comparable with all the treated ones. For 3, 4 and 6 hours the results were different. Except for $\mathrm{T}_{1}$ treatment the length of pollen tubes of controlled ones were comparable with all the treated ones. After growing through the stigmatic tissues the pollen tubes entered into the style (Fig. 2-4). Except for $\mathrm{T}_{0}$ and $\mathrm{T}_{1}$ stylar tissues received a number of pollen tubes (Fig. 5-7). The transmitting tissue of the styles consisted of compacted and elongated cells and the pollen tubes passed through the inter cellular spaces. However, at this interval of time the tubes did not reach the end of the style.

\section{Discussion}

The results indicated that the growth of the pollen tube through the style registered a highly significant increase with both myo-inositol and boron over control at all hours of observations. There was however, little or no differences between the $2^{\text {nd }}$ dose of boron $\left(\mathrm{T}_{2}\right)$ and myo-inositol $\left(\mathrm{T}_{3}\right)$ treatment in this regard, but significant differences exist between $T_{1}$ and $T_{3}$ and $T_{1}$ and $T_{2}$. This clearly signifies the effective dose of treatment for effective tube growth.

One possible outcome of this results is that the infertility problem in late sown wheat can be overcome by external application of boron or myo-inositol. The infertility of seedlessness in wheat was induced by boron deficiency (Ganguly, 1979) which is manifested by the restricted growth of pollen tube through the style (Mandal, 1990). But when borax was sprayed on the florets (BAU 2186) the pollens of Sonalika germinated, pollen tube can successfully grow through the styler transmitting tissues and effect fertilization. Therefore, it can be concluded that in late sown condition the germinated pollen tube had traversed a distance too short to effect fertilization while application of boron and myo-inositol restored fertilization by stimulating the pollen tube growth through style. Jost and Durman (1976) also reported the effect of boron in increasing fertility in wheat. Various workers reported pollen tube inhibition in other ways. Snape et al. (1980), Jalani and Moss (1981), Stich and Snape (1987) reported that the frequency of pollen tube penetration of the ovary wall was severely reduced due to presence of dominant alleles of $\mathrm{Kr}$ locus. Vitlhanage et al. (1980) reported pollen tube incompatibility in Secale cereale was due to callose deposition. But in the present study it will not be out of place to suggest that inhibition of pollen tube penetration through the susceptible stylar tissues may be defect in carbohydrate metabolism pathway mediated by boron (Gauch and Dugger, 1953). The metabolic pathway of myo-inositol had been identified. Myoinositol, a precursor of uronosyl and pentosyl units of cell wall polysaccharides of higher plants including pollen tube wall was utilized for cell wall polysaccharide formation and for synthesis of exudates found on the stigma and style (Kroh et al., 1970).

\section{Conclusions}

For late sown condition of wheat the increase in yield can be obtained by the application of borax on the florets. Reduction of yield at this stage is mainly due to failure of fertilization. However, borax application can induce pollen tube growth through the style and ovarian cells and ultimately fertilization. In similar way myo-inositol can be used as spraying material to ensure crop yield of wheat under late sown condition. However, among these two chemicals use of borax will be more and economical as compared to myo-inositol.

\section{References}

[1]. Brown, C.M., H.L. Shands. 1957. Pollen tube growth, fertilization and early development in Avena sativa. Agron. J. 49:280-288.

[2]. Chandra, S., S.P. Bhatnagar. 1974. Reproductive biology of Triticum. II Pollen germination, pollen tube growth and its entry into the ovule. Photomorphology, 24:211-217.

[3]. Chatterjee, B.N., Chatterjee, M., N. R. Das. 1980. Note on differences in the response of wheat varieties to boron. Ind. J. Agric. Sci. 50:796.

[4]. Cho, J. 1956. Double fertilization on Oryza sativa L. and development of the endosperm with special reference to the aleurone layer. Bull. Natn. Inst. Agric. Sci. Tokyo. 6D. 61-101.

[5]. Ganguly, B. 1979. Note on seedlessness in some wheat varieties caused by boron deficiency. Ind. J. Agric. Sci. 49:384-386

[6]. Gauch, H. G., W.M. Dugger. 1953. The role of boron in the translocation of sucrose. Plant Physiology. 28:457-466. 
[7]. Jalani, B.S., J.P.Moss. 1981. The site of action of crossability genes $\left(\mathrm{Kr}_{1}, \mathrm{Kr}_{2}\right)$ between triticum and secale.II proportion of pistils containing pollen tubes and effects of alternate pollination on seed set. Euphytica. 30:105-112.

[8]. Jost, M., P. Durman. 1976. Potential use of boron preparations for additional fertility restoration in partially restored wheat hybrids. Poljoprivredcna znanstena smotra. 38. 99-104.

[9]. Kihara, H., T. Hori. 1966. The behavior of nuclei in germinating pollen grains of wheat, rice and maize. Zuchter. 36.145-150.

[10]. Kroh, M. H., Miki-Hirosige, W.R., F.A. Loewus. 1970. Incorporation of level into pollen tube walls from myo-inositol labeled Lilium longiflorum pistil. Plant physiology. 45. 92-94.

[11]. Luxova, M. 1967. Fertilization of barley (Hordium distichum L.). Biologia Pl. 9.301-307.

[12]. Mandal, A.B., Sarkar, K.K., Nandeshwar, B.C., Manna, A., Nanda, M.K., S. Some. 2014. Differential varietal response of boron on late sown wheat (Triticum aestivum L.). Journal of Crop and Weed. 7. 232-233.

[13]. Mandal, A.B., A. D. Das 1988. Response of wheat (Triticum aestivum L.) to boron application. Indian J. Agric. Sci. 58. 681-683.

[14]. Mandal, A.B. 1990. Mechanism of florets in compatibility in wheat Triticum aestivum L. Environment and Ecology. 8. $1035-1036$.

[15]. Neumann, M., J. Naether, 1980. Programic incompatibility in cereals. Archiv fur zuchtungs for schung. 3. 179-184.

[16]. Snape, J.W., Benett, M.D., E. Simson. 1980. Post pollination events in crosses of hexaploid wheat with tetraploid Hordeum bulbosum. Zeitchrif fur planzen zuchtung. 85. 202-204.

[17]. Stich, L.A., J.W. Snape. 1987. Factors affecting haploid production in wheat using Hordeum bulbosum. System 1. Genotypic and environmental effects on pollen grain germination, pollen tube growth and the frequency of fertilization. Euphytica 36. 483-496.

[18]. Vitlhanage, H.I.M.V., Gleenson, P.A., A.E. Clarke. 1980. The nature of callose produced during self-pollination in Secale cereal. Planta. 148 : 498-509.

[19]. Zeven, A.C., C. Heermertvan 1970. Germination of pollen of weed rye (Secale segetal) on wheat stigma and the growth of pollen tubes. Euphytica. 19. 175-179.

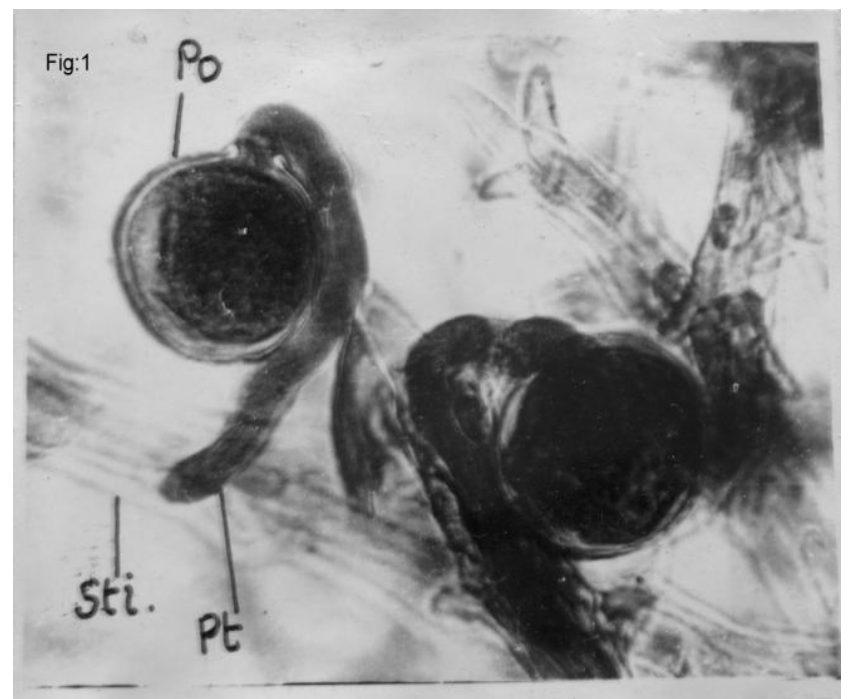

Fig1:Germinating polen on the stigmatic papilla $T_{1}(1)$

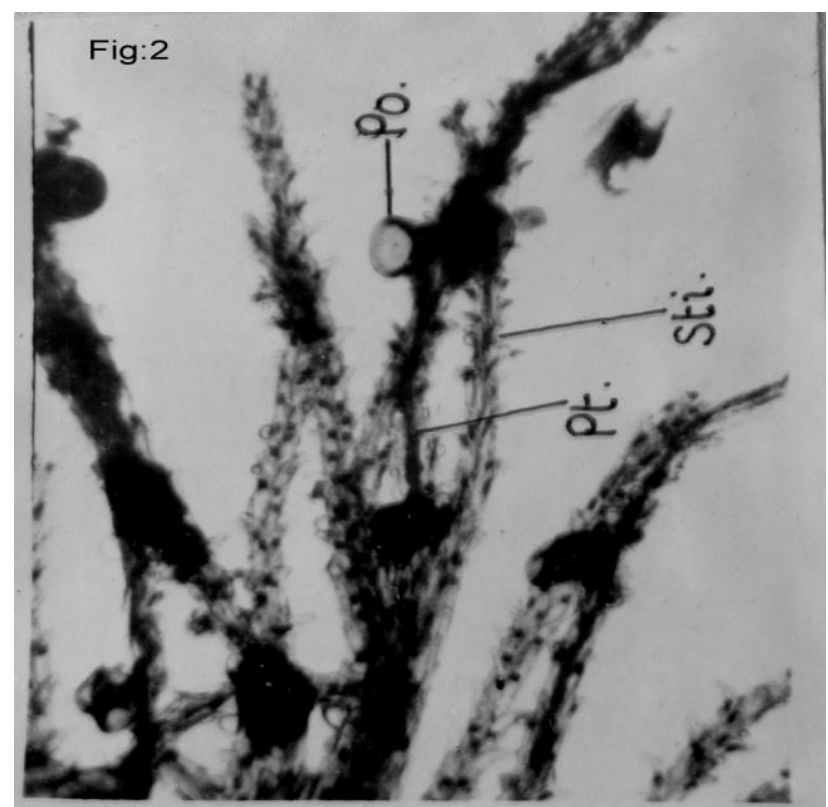

Fig2: Germinating polen on the stigmatic papilla $\mathrm{T}_{0}(3)$ 


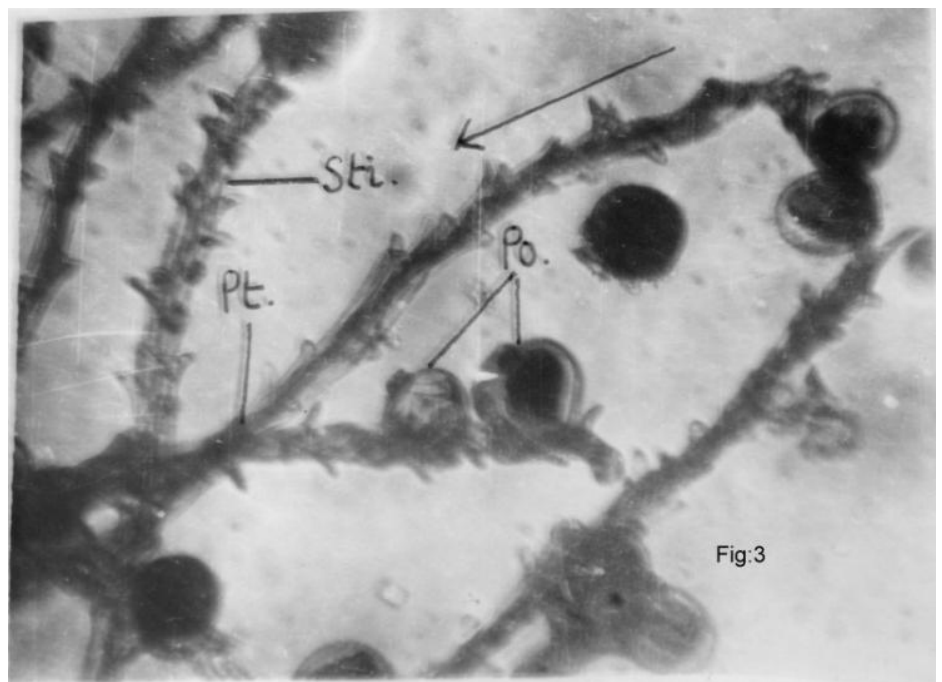

Fig3: Long germinating polen tube on the stigmatic papilla $\mathrm{T}_{2}(3)$

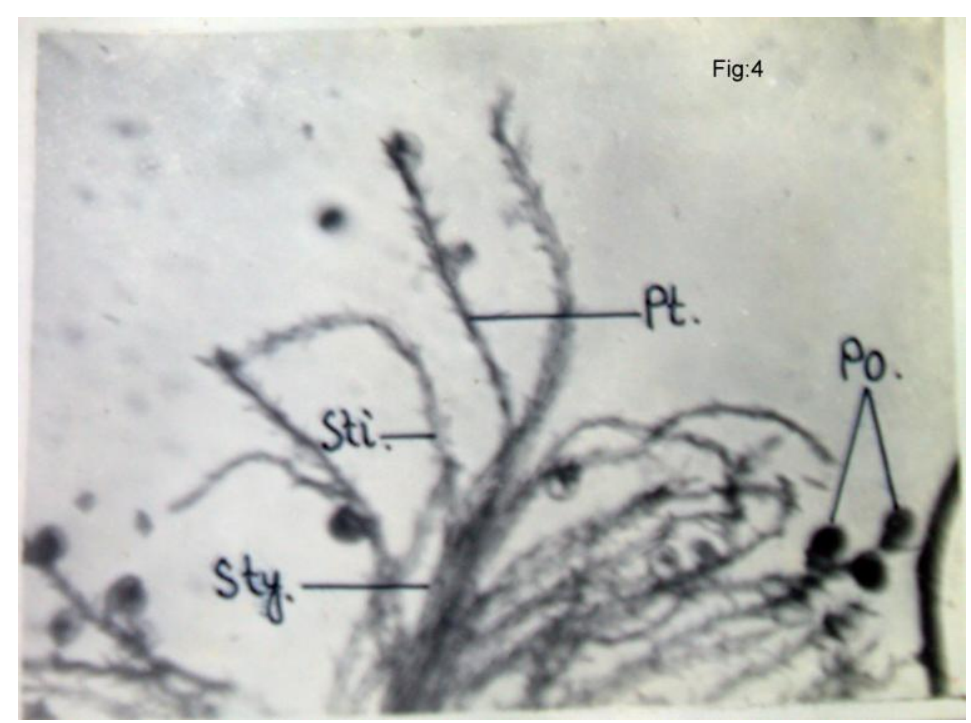

Fig4: Germinating polen tube at the tip of the style $\mathrm{T}_{2}(4)$

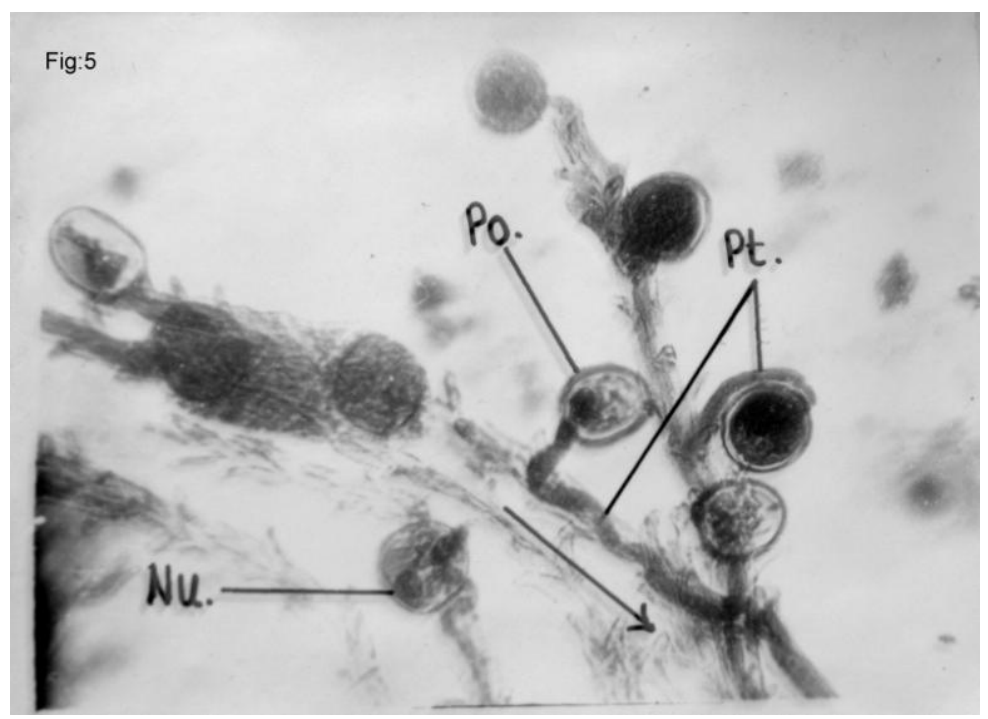

Fig5: Long polen tube ahead of the styler tissue $T_{3}(3)$ 


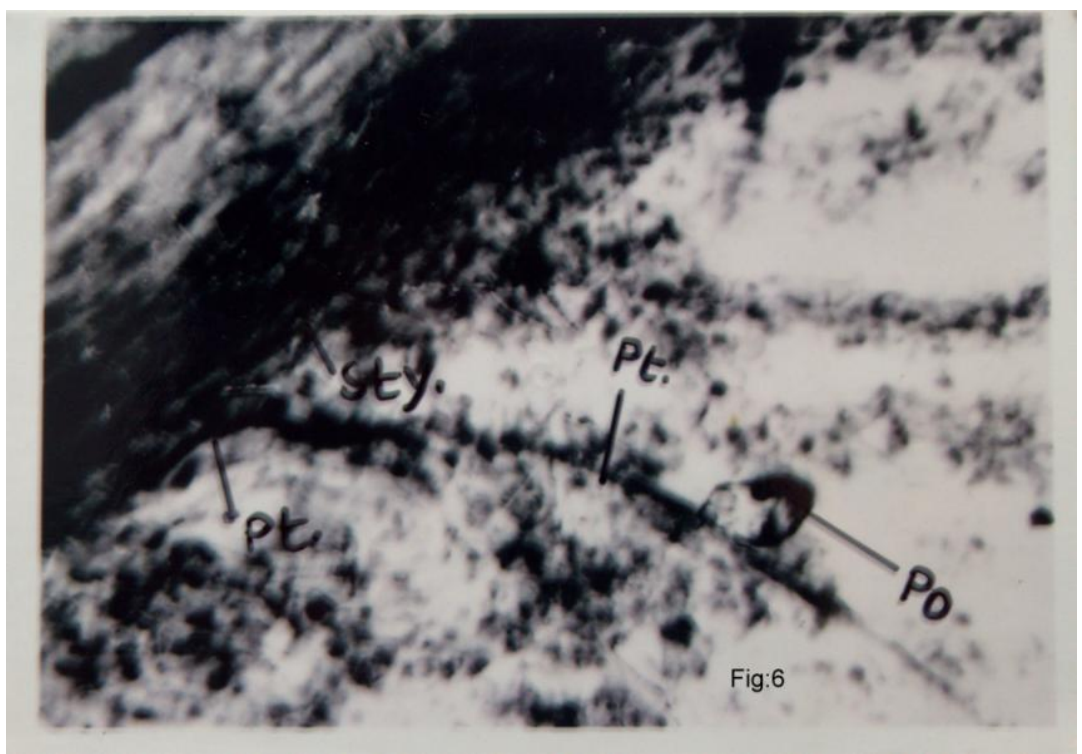

Fig6: Germinating polen tube at the styler tissue $\mathrm{T}_{1}(6)$

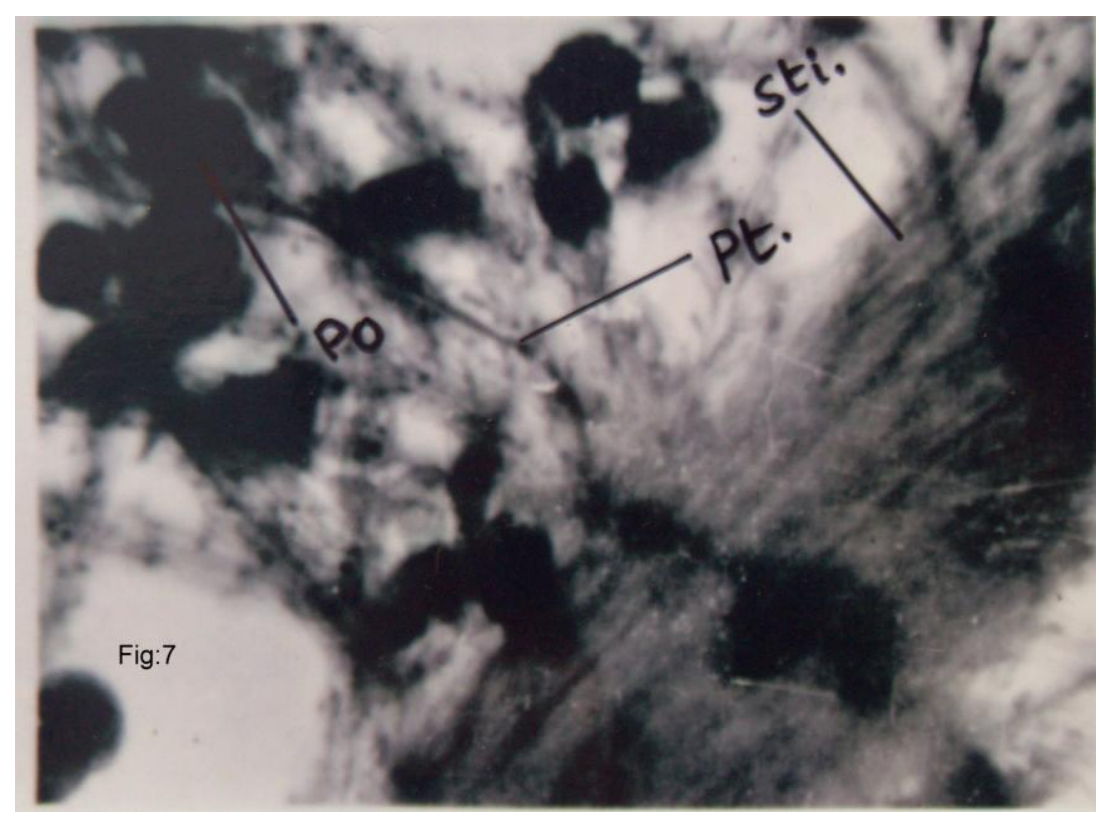

Fig 7: Pole tube at the styler tissues at $\mathrm{T}_{3}(6)$ 